\title{
PERBANDINGAN PERFORMA MESIN DENGAN MENGGUNAKAN SISTEM PENGAPIAN ECM RACING PADA MOTOR NEW CB 150 DAN OLD CB 150

\author{
Jusnita $^{1)}$, Denur ${ }^{2)}$ \\ Program Studi Teknik Industri Universitas Muhammadiyah Riau \\ Jalan Tuanku Tambusai Ujung, Simpang Komersil Arengka (SKA), Kecamatan Tampan, Kelurahan Delima, \\ Delima, Kota Pekanbaru, Riau 28291 \\ e-mail :jusnita@umri.ac.id,denur@umri.ac.id
}

\begin{abstract}
Motorcycles require proper ignition settings to produce the most optimum performance. Re-mapping (re-mapping) in the Electronic Control module (ECM) aims to produce the best torque and power output. The function of the engine control module (ECM) with electronic devices in it is to regulate fuel injection supported by various sensors and actuators to minimize or even eliminate toxins from the combustion of combustion gases from vehicles. The method used is spontaneous throttle testing of the dynotest test equipment ranging from $3000 \mathrm{rpm}$ to $13000 \mathrm{rpm}$. For testing the fuel consumption the throttle method is rotated from $2000 \mathrm{rpm}$ and then increased to $8000 \mathrm{rpm}$ gradually every 1000 rpm increase. The results showed that the maximum torque value using the ECM BRT ignition system on a new Cb motor was $14.1 \mathrm{Nm}$ occurring at $7211 \mathrm{rpm}$ and the maximum power value was $16.4 \mathrm{Hp}$ at $9083 \mathrm{rpm}$. For Old Cb motors, a maximum torque value of 13.84 N.m occurs at 7201 rpm engine speed and a power value of $15.7 \mathrm{hp}$ at $8873 \mathrm{rpm}$ engine speed. So by changing the standard ECM to ECM BRT makes the engine performance increases. For the results of testing exhaust emissions using ECM racing has no effect on $C O$ emission levels
\end{abstract}

Keywords: Motorcycle, ECM ignition system, torque, power, exhaust emissions

\begin{abstract}
Abstrak
Sepeda motor memerlukan pengaturan pengapian yang tepat untuk menghasilkan unjuk kerja yang paling optimum. Pemetaan ulang (re-mapping) pada Electronic Control modul (ECM) bertujuan untuk menghasilkan output torsi dan daya terbaik. Fungsi engine control modul (ECM) dengan perangkat elektronika didalamnya adalah untuk mengatur injeksi bahan bakar yang didukung berbagai sensor dan actuator untuk meminimalkan bahkan menghilangkan racun hasil pembuangan gas sisa pembakaran dari kendaraan. Metode yang digunakan adalah throttle spontan mengujikan alat uji dynotest di mulai dari putaran 3000 rpm sampai 13000 rpm. Untuk pengujian konsumsi bahan bakar metode throttle yang diputar dari 2000 rpm kemudian dinaikkan menjadi 8000 rpm secara bertahap setiap kenaikan 1000 rpm. Hasil penelitian menunjukan bahwa nilai torsi
\end{abstract}

SURYA TEKNIKA Vol. 6 No. 1, Desember 2019: 37-42 
maksimum menggunakan sistim pengapian ECM BRT pada motor new Cb adalah 14,1 Nm terjadi pada putaran mesin $7211 \mathrm{rpm}$ dan nilai daya maksimum 16,4 Hp pada putaran mesin $9083 \mathrm{rpm}$. Untuk motor Old Cb adalah nilai torsi maksimum 13,84 N.m terjadi pada putaran mesin 7201 rpm dan nilai daya 15,7 Hp pada putaran mesin 8873 rpm. Sehingga dengan mengganti ECM standard ke ECM BRT membuat performa mesin meningkat. Untuk hasil pengujian emisi gas buang menggunakan ECM racing tidak berpengaruh pada kadar emisi CO

Kata kunci : Sepeda Motor, Sistim pengapian ECM, Torsi, Daya, Emisi Gas buang

\section{Pendahuluan}

Perkembangan teknologi otomotif semakin maju salah satunya adalah pengembangan mesin kendaraan dengan sistem bahan bakar injeksi (PGMFI) dengan menggunakan kontrol Elektronic Control Modul (ECM). Pengaturan-pengaturan ulang dalam ECM disebut engine remapping ini sangat penting dilakukan untuk mesin yang sudah digunakan lebih dari 5 tahun. Kerusakan pada sensor dan actuator pada mesin menyebabkan performa mesin mengalami penurunan atau meningkatkan performa mesin lebih meningkat dari setingan awal pabrik. Fungsi engine control modul (ECM) dengan perangkat elektronika didalamnya adalah untuk mengatur injeksi bahan bakar yang didukung berbagai sensor dan actuator untuk meminimalkan bahkan menghilangkan racun hasil pembuangan gas sisa pembakaran dari kendaraan. [1] Kekurangan pada ECM adalah tidak dapat di setting. Untuk mengoptimalkan pada performa Honda New CB 150 (sampai batas max standard) bisa dilakukan dengan cara mengupgrade atau mengganti pengapian ECM

\section{Metodologi}

Metode yang digunakan dalam penelitian ini adalah metode throttle spontan mengujikan alat uji dynotest di mulai dari putaran 3000 rpm sampai 13000 rpm. Untuk pengujian konsumsi bahan bakar metode throttle yang diputar dari $2000 \mathrm{rpm}$ kemudian dinaikkan menjadi $8000 \mathrm{rpm}$ secara bertahap setiap kenaikan 1000 rpm [3]. Sedangkan untuk pengujian emisi gas buang menggunakan alat gas analyzer.

\section{Hasil dan Pembahasan}

sehingga performa pada Honda New CB 150 dan Old $\mathrm{Cb} 150$ akan menjadi maksimal dan bertenaga dari standard pabrik. Sistem pengapian standard yang digunakan pada sepeda motor New CB 150 dan Old CB adalah Full ransistered Honda New cb 150 memiliki daya $\max 15,7 \mathrm{HP} / 9000 \mathrm{Rpm}$, Torsi $\max 13,8$ NM/7000Rpm, sedangkan Old $\mathrm{Cb}$ memiliki daya max 15 HP/8558 Rpm, Torsi max 13,49 NM/7243 Rpm [2]

Berdasarkan fenomena tersebut penggantian komponen ECM standard dengan ECM racing BRT hyperband adalah salah satu cara untuk mendapatkan pengapian yang lebih baik sehingga diharapkan terjadi pembakaran yang sempurna. Pembakaran yang sempurna akan menghasilkan daya, torsi yang stabil dan optimal serta konsumsi bahan bakar yang efisien. Maka dalam hal ini perlu dilakukan penelitian terhadap sistem pengapian agar dalam proses pembakaran menjadi lebih baik, konsumsi bahan bakar yang efisien dan kinerja mesin yang lebih optimal.

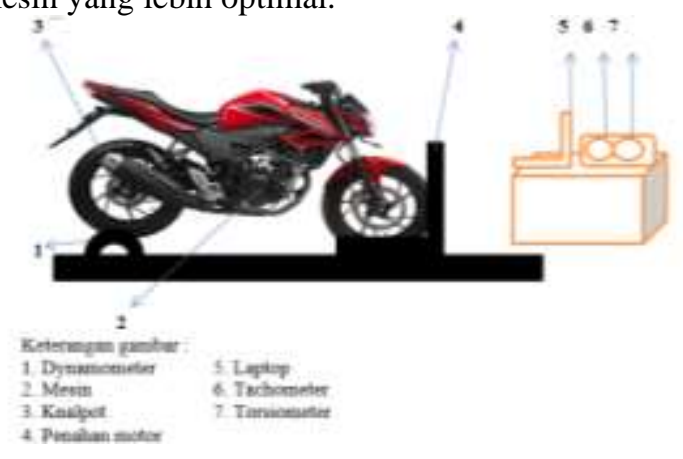

Gambar 1. Setup Alat Pengujian

Hasil pengujian performa mesin menggunakan alat uji dynotest pada sepeda motor New $\mathrm{Cb}$ dan Old $\mathrm{Cb}$, seperti pada gambar grafik dibawah ini :

SURYA TEKNIKA Vol. 6 No. 1, Desember 2019: 37-42 
ISSN: 2354-6751

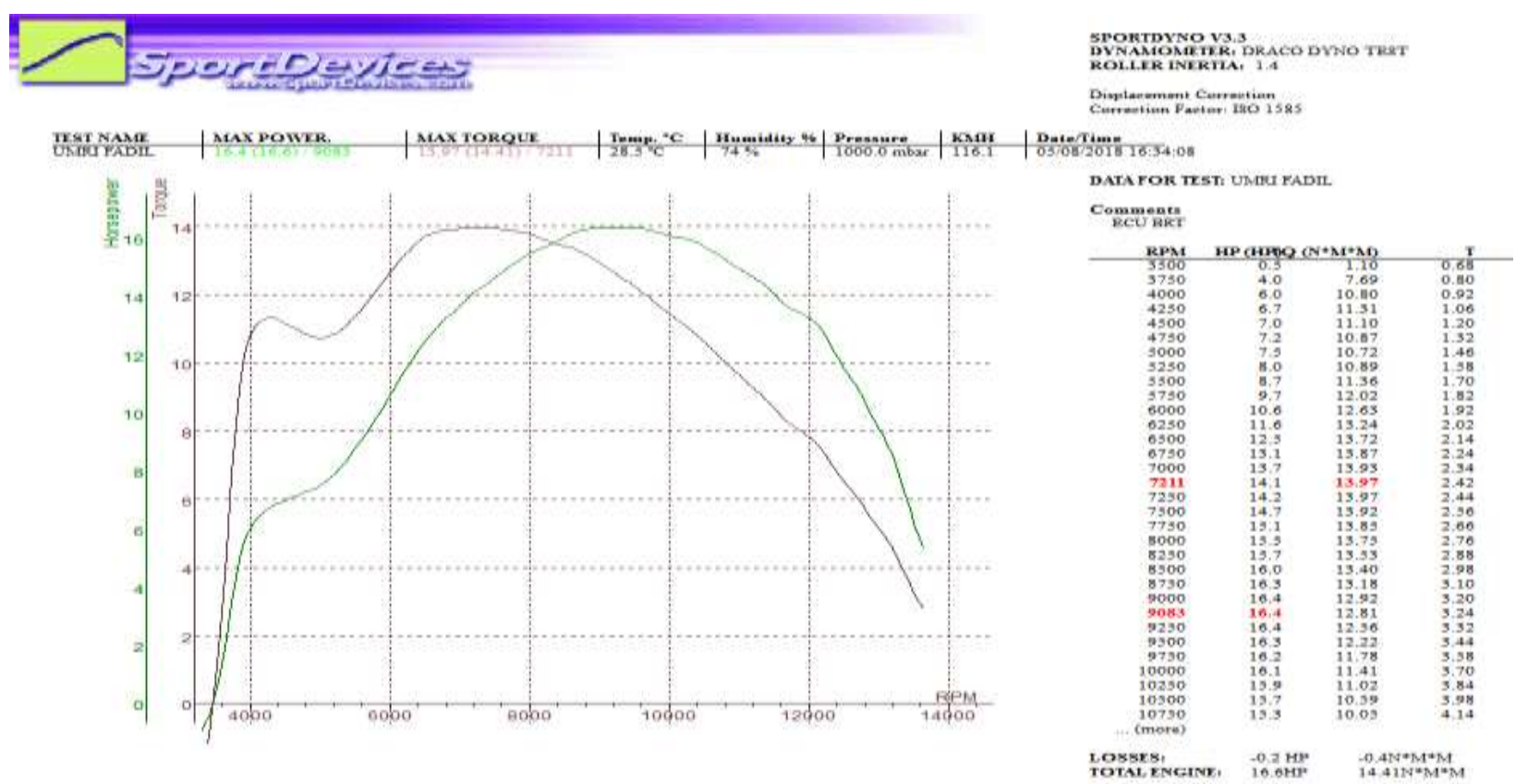

Gambar 2 Grafik pengujian daya vs torsi sepeda motor New Cb 150

Pada gambar 1 hasil pengujian pada putaran 3500 rpm menghasilkan daya minimal $0,5 \mathrm{Hp}$ dan maksimal 16,4 Hp terjadi pada putaran mesin $9083 \mathrm{rpm}$. Setelah itu daya cenderung menurun seiring dengan bertambahnya putaran mesin. Dari hasil pengujian, torsi minimum 1,1 terjadi pada putaran $3500 \mathrm{rpm}$ dan torsi maksimum 13,97 Nm di Rpm 7211 dan torsi menurun seiring dengan bertambahnya putaran mesin. Kecepatan kendaraan akan terus naik, namun power dan torsi kendaraan akan turun karena sudah mencapai titik maksimal (peak power).

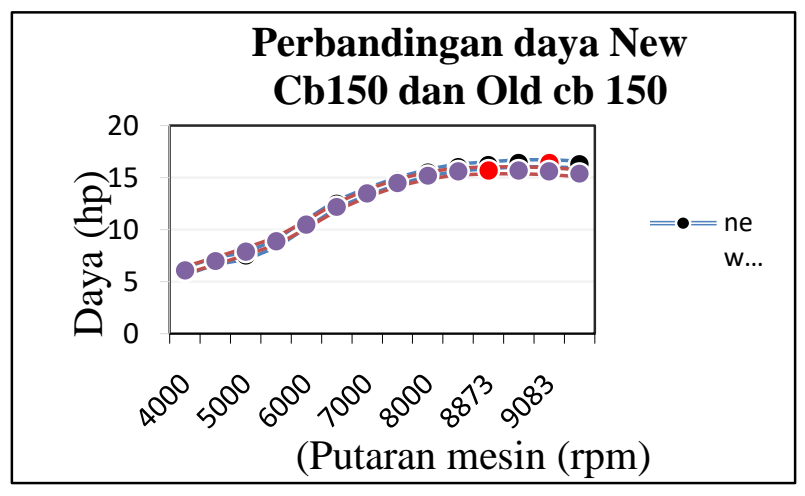

Gambar 2. Grafik Putaran mesin vs Daya

SURYA TEKNIKA Vol. 6 No. 1, Desember 2019: 37-42 
ISSN: 2354-6751

Pada gambar grafik 4.3 menunjukkan grafik hubungan antara kecepatan putaran mesin vs daya dengan kondisi mesin standar dengan menggunakan sistem pengapian ECM BRT juken 5 hyperband. Daya maksimal motor new $\mathrm{Cb} 150$ adalah 16,4 Hp pada putaran mesin $9083 \mathrm{rpm}$. Sedangkan daya maksimal yang didapatkan oleh motor Old $\mathrm{Cb}$ adalah sebesar 15,7 Hp pada putaran mesin $8873 \mathrm{rpm}$. Maka dapat diambil kesimpulan daya tertinggi didapatkan oleh new $\mathrm{Cb}$ dengan menggunakan ECM racing BRT juken 5 hyperband. Hal tersebut terjadi karena ECM BRT memiliki ketepatan pengapian yang baik serta ECM tidak diberikan limiter. Sehinga Rpm bisa dinaikkan sesuai dengan standard mesin new cb dan Old $\mathrm{Cb} 150$. Pada sistem pengapian racing pembakaran yang terjadi pada ruang bakar lebih baik dibandingkan dengan menggunakan sistem pengapian standard.

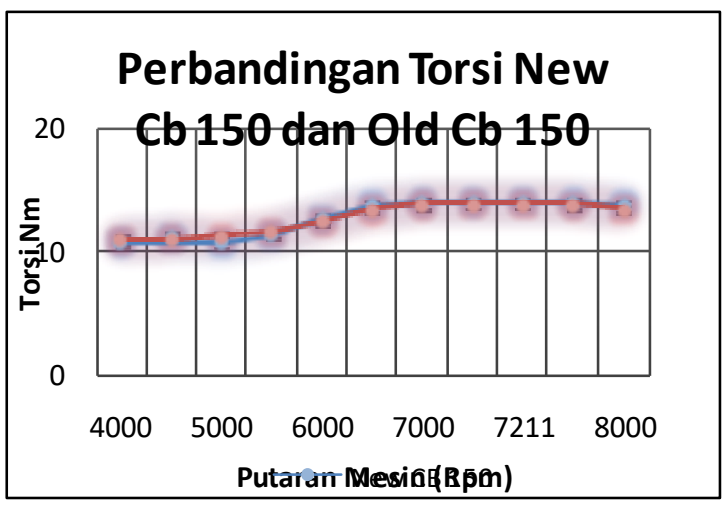

Gambar 3. grafik perbandingan putaran mesin vs torsi

Pada kecepatan putaran mesin rendah daya meningkat sampai di titik puncak kisaran 9083 Rpm untuk motor New $\mathrm{Cb}$. Pada motor Old $\mathrm{Cb}$ daya meningkat sampai kisaran 8873 Rpm.

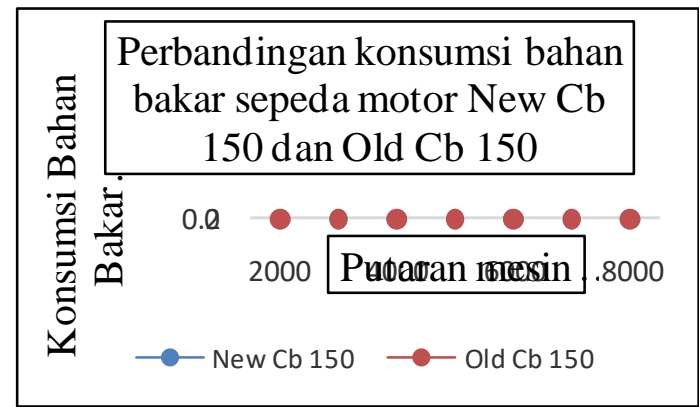

Gambar 4. grafik perbandingan putaran mesin vs konsumsi bahan bakar

Pengujian emisi gas buang menggunakan alat gas anlyzer dengan bahan bakar octane number ron 95 .

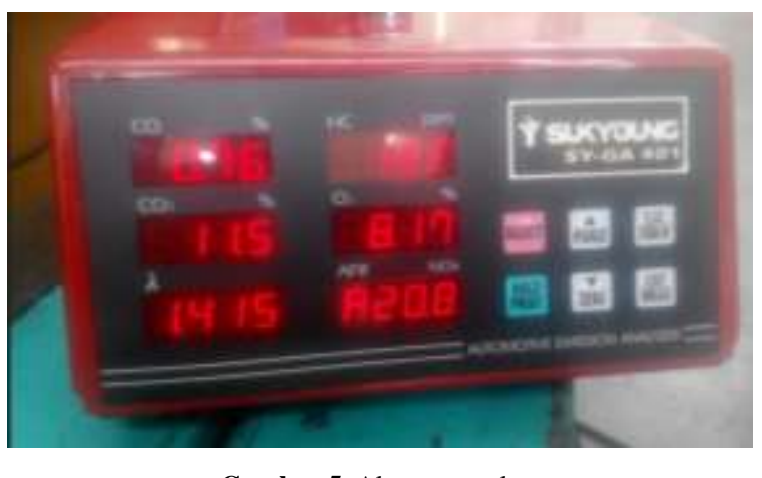

Gambar 5. Alat gas analyzer New $\mathrm{Cb} 150$ dan Old $\mathrm{Cb}$

Pengujian ini dilakukan tiga kali tahap pengujian pada masing masing motor, dimana dilakukan pada putaran yang berbeda mulai dari rpm 2500, 5000, 8000 Rpm dengan bahan bakar octane number 95. Untuk motor New $\mathrm{Cb}$ pada putaran $2500 \mathrm{Rpm} \mathrm{CO}=0,01 \%$, putaran $5000 \mathrm{Rpm} \mathrm{CO}=0,01 \%$ dan pada putaran 8000 $\mathrm{Rpm} \mathrm{CO}=0,02 \%$. Sedangkan pada motor Old $\mathrm{Cb}$ diuraikan mulai dari Rpm $2500 \mathrm{CO}=0,03 \%$ kemudian di Rpm $5000 \mathrm{CO}=0,12 \%$ dan pada putran Rpm 8000 $\mathrm{CO}=0,12 \%$.

SURYA TEKNIKA Vol. 6 No. 1, Desember 2019: 37-42 


\section{Simpulan}

Kesimpulan yang dapat diambil pada penelitian ini adalah : nilai torsi maksimum menggunakan sistim pengapian ECM BRT pada motor new Cb adalah 14,1 Nm terjadi pada putaran mesin $7211 \mathrm{rpm}$ dan nilai daya maksimum 16,4 Hp pada putaran mesin $9083 \mathrm{rpm}$. Untuk motor Old $\mathrm{Cb}$ adalah nilai torsi maksimum 13,84

\section{Daftar Pustaka}

[1] Ahmad Muhajir UU Mesin Sepeda Motor 4 Langkah 110cc pada Berbagai Tekanan Kompresi.

[2] Ilham Eka Fitriyanto, (2016) Pengaruh Campuran Minyak Plastik Low Density Polythiline Dengan Pertalite Terhdap Performa Mesin Sepeda Motor.
N.m terjadi pada putaran mesin $7201 \mathrm{rpm}$ dan nilai daya 15,7 Hp pada putaran mesin $8873 \mathrm{rpm}$. Sehingga dengan mengganti ECM standard ke ECM BRT membuat performa mesin meningkat. Untuk hasil pengujian emisi gas buang menggunakan ECM racing tidak berpengaruh pada kadar emisi $\mathrm{CO}$

[3] JokodanPetrus . (2015). Analisa kinerja mesin bensin berdasar kanper bandingan pelumas mineral dan sintetis. Universita pasir pengaraian.

SURYA TEKNIKA Vol. 6 No. 1, Desember 2019: 37-42 